\title{
Collaboration Between ESL and Content Teachers: How Do We Know When We Are Doing It Right?
}

\author{
Chris Davison \\ Faculty of Education, University of Hong Kong, Hong Kong
}

Partnership and the integration of language and content teaching in English-medium schools have long been active areas of research and inquiry in applied linguistics and TESOL. However, most researchers have tended to focus on methods and techniques to use in the classroom or on the analysis of the linguistic demands of the content areas. Much less attention has been paid to researching the process of coplanning and co-teaching and to supporting the evolution of the partnership between ESL and content teachers. This paper draws on questionnaire and interview data collected as part of a school-based professional development initiative in an English-medium school in Asia that focused on developing more collaborative relationships between ESL and content/classroom teachers in a large culturally and linguistically diverse elementary school. The paper begins with an analysis of some of the underlying assumptions in current conceptualisations of effective collaboration between ESL and mainstream/content-area teachers, then presents an emerging framework that draws on teacher talk and critical discourse analysis to describe and evaluate the stages of collaboration and the different levels of its effectiveness. The implications of this research for evaluating approaches to partnership and for setting realistic goals for professional development and institutional change will also be explored.

doi: $10.2167 /$ beb339.0

Keywords: English as Second Language, mainstreaming, team teaching, collaboration, discourse

\section{Introduction}

The development of greater collaboration or 'partnerships' between English as a Second/Additional Language (ESL/EAL) teachers and their mainstream/ content-area colleagues has long been advocated in the English language teaching profession. It has received greatest policy and structural support in England through the development of an explicit model of Partnership Teaching (Bourne, 1989; Bourne \& McPake, 1991), which builds on a model of cooperative teaching, but goes beyond that. As Bourne (1997: 83) argues:

Partnership Teaching is not just another term for 'co-operative teaching'. Co-operative teaching is where a language support teacher and class or subject teacher plan together a curriculum and teaching strategies which will take into account the learning needs of all pupils, trying to adjust the 
learning situation to fit the pupils. Partnership Teaching is more than that. It builds on the concept of co-operative teaching by linking the work of two teachers, or indeed a whole department/year team or other partners, with plans for curriculum development and staff development across the school.

Over the last 20 years most English-medium schools around the world have adopted some form of partnership or collaborative teaching to enhance the integration of ESL/EAL students into the mainstream classroom and to develop more language-conscious approaches to teaching. For example, in Australia, in response to state government policy and student need, a major thrust of the school ESL programme is now support and team teaching in the mainstream classroom (Davison, 2001a). In Canada too there has been a longestablished tradition of collaborative teaching in ESL contexts (Early, 2001). Increasingly such collaborative models are also being widely promoted in international schools around the world (Hurst \& Davison, 2005) as well as in the tertiary sector (Crandall \& Kaufmann, 2002; Mohan \& Lowe, 1995). There is a small but growing number of in-service education initiatives and research studies in this area, but surprisingly perhaps, most of this work has tended to focus on methods and techniques to use in the classroom or on the analysis of the linguistic demands of the content areas (Brinton \& Master, 1997; Brinton et al., 1989; Crandall, 1987; Crandall et al., 1987; Mohan, 1986). Only very recently has much attention been paid to researching the process of coplanning and co-teaching and to supporting and evaluating the development of partnership between ESL/EAL and content-area teachers (see for example, Arkoudis, 2000, in press; Arkoudis \& Davison, 2002; Creese, 2000, 2002; Gardner, this volume).

This paper argues that partnership as a model of ESL/EAL delivery is still relatively undertheorised and needs further evaluation and reconceptualisation if it is to be effective. One of the major impediments to this development is the lack of criteria for evaluating the effectiveness of collaborative teaching generally. This paper focuses on the question of how to judge if and when collaborative teaching is effective, and the implications of this for professional development and institutional support. The paper draws on questionnaire and interview data collected as part of a school-based professional development initiative in an English-medium school in Asia that focused on developing more collaborative relationships between ESL and content/classroom teachers in a large culturally and linguistically diverse elementary school. The paper begins with an analysis of some of the underlying assumptions in current conceptualisations of effective collaboration between ESL and mainstream/ content-area teachers, then presents an emerging framework which draws on critical discourse analysis of teacher talk to describe the stages of collaboration and levels of development in one particular elementary school. The implications of this research for evaluating approaches to partnership and for setting realistic goals for professional development and institutional change will also be explored. 


\section{Key Assumptions about Effective Collaboration between ESL and Content-area Teachers}

There are a number of essential elements for effective collaboration between language and content-area teachers, which have been discussed elsewhere (see, for example, Davison, 1992; Hurst \& Davison, 2005), including the need to establish a clear conceptualisation of the task, the incorporation of explicit goals for ESL development into curriculum and assessment planning processes, the negotiation of a shared understanding of ESL and mainstream teachers' roles/responsibilities, the adoption of common curriculum planning proformas and processes, experimentation with diversity as a resource to promote effective learning for all students, the development of articulated and flexible pathways for ESL learning support, and the establishment of systematic mechanisms for monitoring, evaluation and feedback.

The first of these elements - a clear conceptualisation of the task - is the most fundamental. Experience demonstrates that all too often collaborative teaching is seen as simply a case of another pair of hands; an attitude that 'two teachers are better than one. ${ }^{1}$ In such theorisations of collaboration, teachers are simply doubled rather than differentiated. Often such partnerships are associated with the subordination of ESL to the content area and an imbalance between teachers in terms of curriculum authority, responsibility and opportunities for input (for example, see Arkoudis, this volume; Davison, 2001c for a fuller discussion).

Such imbalances and biases in the conceptualisation of partnership are found at the system level as well, for example, in the orientation of the ESL in the Mainstream in-service course (Education Department of South Australia, 1991), widely adopted in Australia and Britain as well as in Hong Kong to support collaboration between ESL and content-area teachers. Although widely endorsed as an effective professional development activity, the course projects an image of ESL expertise as residing in methodology or strategies, rather than in curriculum content (curriculum being discussed only in relation to cultural inclusiveness). A prior, shared understanding of ESL curricular goals is either assumed or not considered to be significant. Paradoxically, the focus on 'how' rather than 'what' is both a major strength and weakness of the course. It is a strength because it makes the course very practical and attractive to teachers and gives them hands-on skills and techniques. On the other hand, the lack of attention to the underlying principles of ESL, its disciplinary content and the very different, even conflicting cultural and belief systems of ESL and subject area teachers may lead to teachers recontextualising, distorting or transforming many of the techniques or strategies actually targeted in the course. ${ }^{2}$ This weakness is exacerbated by the widespread assumption that ESL teachers need no guidance in developing collaborative relations, other than a sympathetic and supportive school environment and cooperative partners.

This author has argued elsewhere that for partnership to be most effective, the collaborative task - of planning, teaching and evaluating - needs to be concerned with broader notions of curriculum, rather than just methodology 
or materials (see Davison, 2001b, 2001c; Davison \& Williams, 2001). An ideal collaboration between ESL and content-area teachers requires the integration of content-based ESL teaching and ESL-conscious content teaching (Crandall, 1987; Davison \& Williams, 2001; Leung, 2001), that is, systematic planned language development, not just the inclusion of ESL students in the ongoing activities of the mainstream classroom. This is best captured by the framework for integration below (see Figure 1).

This framework presumes that in any collaboration between ESL and content teachers there are at least two curricula: an ESL description of stages of development, linked to broad levels of schooling and age, and a content-area curriculum (or in the case of many elementary programmes, a set of curricula). However, research shows that incorporating language objectives into content lessons is challenging (Short \& Echevarria, 1999), because content specialists immersed in the discourse of their discipline do not easily recognise the language demands of curriculum, let alone the language-learning needs and opportunities, whilst ESL teachers struggle to 'cover the content' and easily lose direction and control.

This brings us to the key question addressed in this paper, that is, how to systematically describe and evaluate collaborative relationships and their development as part of the establishment of an explicit mechanism for monitoring, evaluation and feedback. This is important not only to establish clear expectations for teachers and the wider school community, for example, by identifying indicators of successful (and less successful) partnerships, but also in order to support and shape such partnerships as they develop. There is little previous research on this issue, partly because the concept of collaboration in educational institutions is itself undertheorised and under-researched.

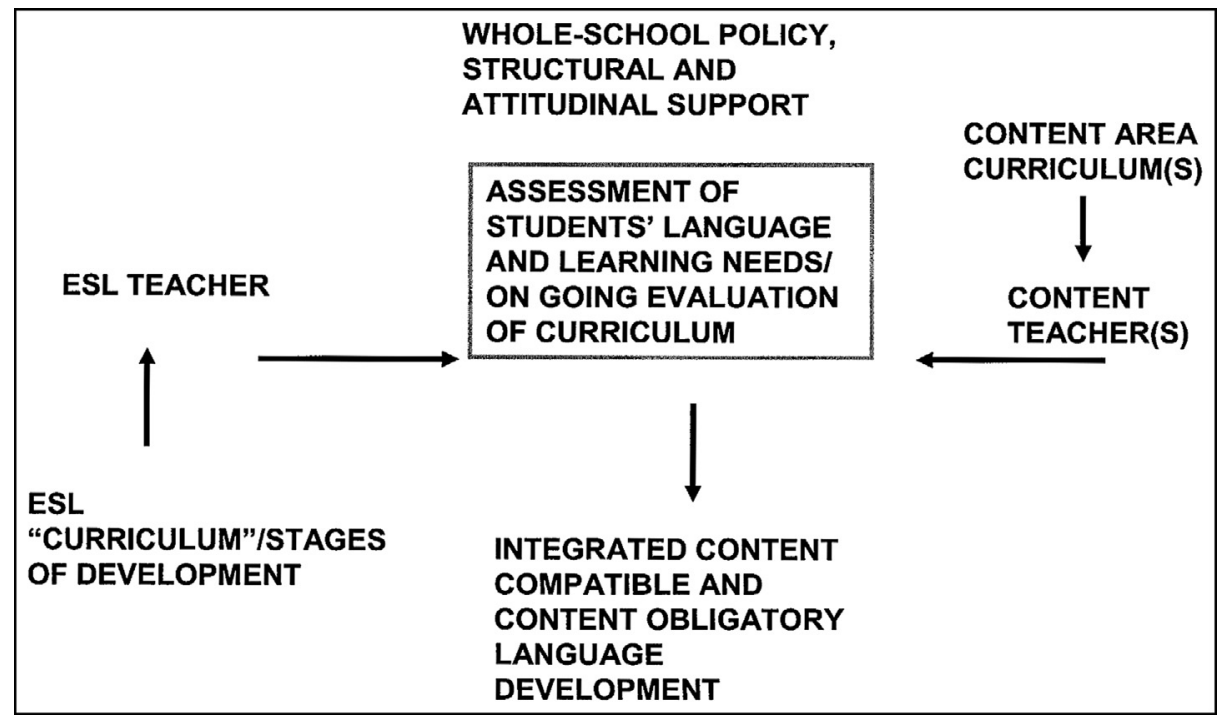

Figure 1 A conceptual framework for integrated language and content instruction Adapted from: Snow et al. (1989: 205) 
The next section of this paper will examine the problematic nature of collaboration and its development in educational contexts in general.

\section{The Problematic Nature of Collaboration and its Development}

Teacher collaboration is promoted as a panacea for many ills, from breaking down the professional isolation of the classroom to compensating for inadequate professional development to salving the wounds wrought by overly ambitious curriculum reform (Corrie, 1995; Hargreaves, 1994; Hargreaves \& McMillan, 1994; Little, 1990). To some critics teacher collaboration is yet another poorly conceived but increasingly popular imposition on teachers from above, a contrived collegiality (Hargreaves, 1994: 208):

In contrived collegiality, collaboration amongst teachers was compulsory, not voluntary; bounded and fixed in space and time; implementationrather than development-orientated; and meant to be predictable rather than unpredictable in its outcomes.

The literature suggests, however, that effective collaboration between teachers is not only rare, but extremely difficult to sustain. As Little (1990: 180) comments:

The closer one gets to the classroom and to the central questions of curriculum and instruction, the fewer are the recorded instances of meaningful, rigorous collaboration.

Only one quarter of teachers surveyed by Lortie (1975: 194) reported having frequent contact with other teachers to plan joint classes, review students' work or team-teach. Collegial relations are seen as fragile and unstable (Little, 1990), requiring strong incentives and support from the administration, careful planning and coordination of teaching loads, and above all, sufficient resources and structured allocated time to allow experimentation and the building of strong interpersonal relationships. In partnerships between classroom and special education teachers, Hargreaves (1994) also found concerns about expertise interwoven with issues of ownership and control, with personality clashes and resistance to advice common. As Roth and Tobin (2004: 165) argue, 'co-teaching is not just a way of going about the everyday work of accomplishing a teacher's task but, equally important, it is a way of changing the way one teaches.' This can be very uncomfortable, even threatening, especially if the co-teaching has been mandated, rather than freely chosen. In such situations, Hargreaves (1994: 204) argues, it is essential that:

Sharing should not be construed as sharing among the skilled and less skilled, the expert and the novice, but among communities of professional equals committed to continuous improvement.

A more positive way to look at collaboration is to link it to the development of teacher expertise more generally, to see it as an essential aspect of the postmodern teacher's role. Over the last four decades there have been 
numerous studies concerning the development of expertise in teaching, both at the preservice and inservice level (Burden, 1990; Calderhead \& Shorrock, 1997; de Jong, 2000; Fuller \& Brown, 1975; Furlong \& Maynard, 1995; Tsui, 2003). Fuller and Brown (1975) found that beginning teachers normally progressed through four stages, starting with few, if any, concerns at the preservice level, then passing through sequential stages of survival self-concerns, teaching concerns and learning concerns. Initially struggling to adapt to routines and reluctant to change, teachers gradually become more concerned about their impact on pupils, then ready to respond to feedback on teaching. This model of development, moving from self-concerns to task management to learner impact and teaching innovation has been confirmed in many other studies as a typical development pattern for novice teacher growth (Calderhead \& Shorrock, 1997; Furlong \& Maynard, 1995; Kagan, 1992). Research shows that developing teachers do not necessarily think about different things, but about the same things differently.

Many stage models have also emerged in the literature on serving teachers and their development of expertise (Berliner, 1986; Burden, 1990; Kagan, 1992). Berliner (1986), one of the first working in this area, proposed a five-stage model for the development of teacher expertise that combined teachers' observable instructional performances and underlying teacher cognition. The first two stages were characterised by deliberation in action and thinking as well as by a reluctance to take full responsibility for their actions. In contrast, the third stage, competence, was marked by more deliberate and conscious actions and rational goals. The two highest stages, proficient and expert, were marked by increasing levels of intuition, fluidity and 'knowing-in action'. Berliner's research also suggested that teachers generally progress at different speeds and do not necessarily become even proficient, let alone expert. Similar findings are reported in studies of the role of reflection in the development of expertise (Ghaye \& Ghaye, 1998; Van Manen, 1997; Zeichner \& Liston, 1996) with development again being seen as a series of stages, ranging from the technical descriptive, to the practical interactive to the highest level, critical reflection. Parallels to this notion of different stages of development are found in the literature on stages of concern in teachers' response to innovation and change (see for example, Cheung \& Ng, 2000).

Like Arkoudis (this volume), this study is particularly interested in analysing the discourse of collaborating teachers to understand their key concerns, and to analyse whether there are any patterns in the concerns of more or less successful partnerships, in order to develop a model of the different stages of collaboration between ESL and classroom teachers. As Arkoudis (this volume) has argued, ESL and classroom/content-area teachers belong to distinct discourse communities, each with their own often-implicit assumptions and beliefs about their subject area and its importance within the school curriculum. In Hargreaves and McMillan's (1994: 213) words, 'collaboration can connect, but it can just as easily divide.' Hargreaves and McMillan (1994) talk about the balkanisation of teaching, in which teachers may collaborate but only within smaller subcommunities in the school. These communities are characterised by low permeability but high permanence, selfinterest, and identification with the sub-community rather than with the 
school as a whole, which 'undermines the capacity for empathy and collaboration with others' (Hargreaves \& McMillan, 1994: 214). Siskin (1994) found concrete examples of this phenomenon in the secondary school, with curriculum content and subject knowledge seen as belonging to teachers from that discipline. Teachers identified most strongly with their teaching area, creating a we/them discourse in their work-related talk. However, as Arkoudis points out, Siskin's research did not address how the epistemological assumptions that are entrenched within the nature of subject disciplines can influence cross-disciplinary discourse. This paper explores to what extent such epistemological, even ideological, assumptions are a factor in the development of collaboration in a elementary school context, given that the notion of subject boundaries and disciplines has traditionally been much more fluid and diffuse in the elementary sector with its long history of integrated teaching and its reliance on general classroom teachers, rather than disciplinary specialists, to teach most core subject areas.

It needs to be emphasised that for this research study it was the discourse of the partnership that was analysed, not the competence of the individual teacher. It was assumed from the outset that two highly competent teachers do not necessarily make for a successful partnership. As Gardner's work (this volume) suggests, successful collaboration may occur between two teachers with very different status and roles who, through implicit or explicit negotiation, develop a strong and sustainable partnership. The setting, informants and research design of the current study will now be described.

\section{The Study: Overall Approach, Context and Informants}

The study reported here was part of a larger research project investigating the integration of English language and content-area teaching in Englishmedium international schools in the Asia-Pacific region (for example, see Hurst \& Davison, 2005). This study draws on questionnaire and interview data collected as part of ongoing school-based professional development and curriculum change in a large K-12 English-medium international school in Taiwan. The students were from more than 50 different nationalities, with the majority Chinese-speaking with strong links to the Taiwanese American community, either returnees or locally born children of American passport holders. The teachers were even more diverse, with many recruited from the USA, Canada, Australia and New Zealand or other international schools in the region. They were highly qualified and generally very experienced working in ESL contexts. The curriculum adopted was American in origin, but with many local adaptations.

The school had initiated contact with the researcher who worked with the faculty over a period of three years to first evaluate the existing effectiveness of the ESL/Language Arts programme in catering for a linguistically and culturally diverse population, then working with groups of teachers to implement specific aspects of English language and content integration across the curriculum. The data presented here were collected from the elementary school (Grades 1-5), which was organised into about four to five classes of 20-22 students per year level. A number of ESL teachers had been working 
with elementary-aged students for many years on a pull-out basis, but the elementary school now wanted to implement a more collaborative approach to curriculum planning, teaching and assessment. The administration sponsored professional development days that explored issues such as the role of the ESL teacher, the stages of second-language development and the impact of different ESL-conscious approaches on teaching and learning. One of the results of the professional development work was the development of an agreement on ESL and content-area roles and responsibilities, a draft K-12 document (see Table 1) that affirmed the expertise each teacher had to offer, and was deliberately designed to be continually renegotiated by teachers through regular evaluations, small group meetings and individual interaction. Another important outcome was the development of a common planning proforma for units of work that encouraged both ESL and content teachers to develop common goals and activities.

The data discussed in this paper were collected through a short open-ended questionnaire and follow-up semi-structured interviews and focused observations at the end of the year of collaboration. The study involved 12 teachers from Grades 1, 2 and 5 (identified in the analysis as classroom teachers (CT 1-12) working in partnership with 5 ESL teachers (identified as ESL 1-5). The methodological approach chosen was primarily qualitative and interpretive, using grounded theory as a way of generating a theoretical model of collaborative development. The theoretical framework for analysis was influenced by the work of Lave and Wenger (1991) on learning communities and Halliday (1985) and Martin's (1992) view of language as a social resource for meaning-making.

Once the data were collected, they were analysed in a number of stages. In keeping with the ethnographic orientation of this study, this process was ongoing, recursive and iterative (Seliger \& Shohamy, 1989: 210). As a first step in the process, the data were copied, organised and grouped into a preliminary categorisation suggested by the themes arising during the course of data collection, as well as by my own 'tacit knowledge' and empiricised propositions (Stake, 1978: 6) about collaboration and its development; then a process of 'systematic inquiry into the data' (Miles \& Huberman, 1984) was undertaken. Gradually, as clearer patterns emerged as to what teachers seemed to be saying and doing and why, I sought a more systematic analytical framework to describe their discourse. This meant I moved back and forth between my specific data and the related research literature, experimenting with and discarding different models of analysis and trialling different coding systems. In this sense, my analytical framework was not predetermined nor imposed; it was grounded in the data (Glaser \& Strass, 1967). Ultimately I found Halliday's (1985) work on field, tenor and mode, and Martin's (1986a, $1986 b, 1992)$ extension of those concepts to analyse the genre or purpose of the social situation the most useful analytical tool for describing the teachers' specific discourse within the social, cultural and disciplinary context in which the interaction occurred. However, I felt much discourse analysis was limited by its failure to ask the text 'participants', the teachers, what they knew and what they thought they were doing. As Thesen (1997: 504) argues: 


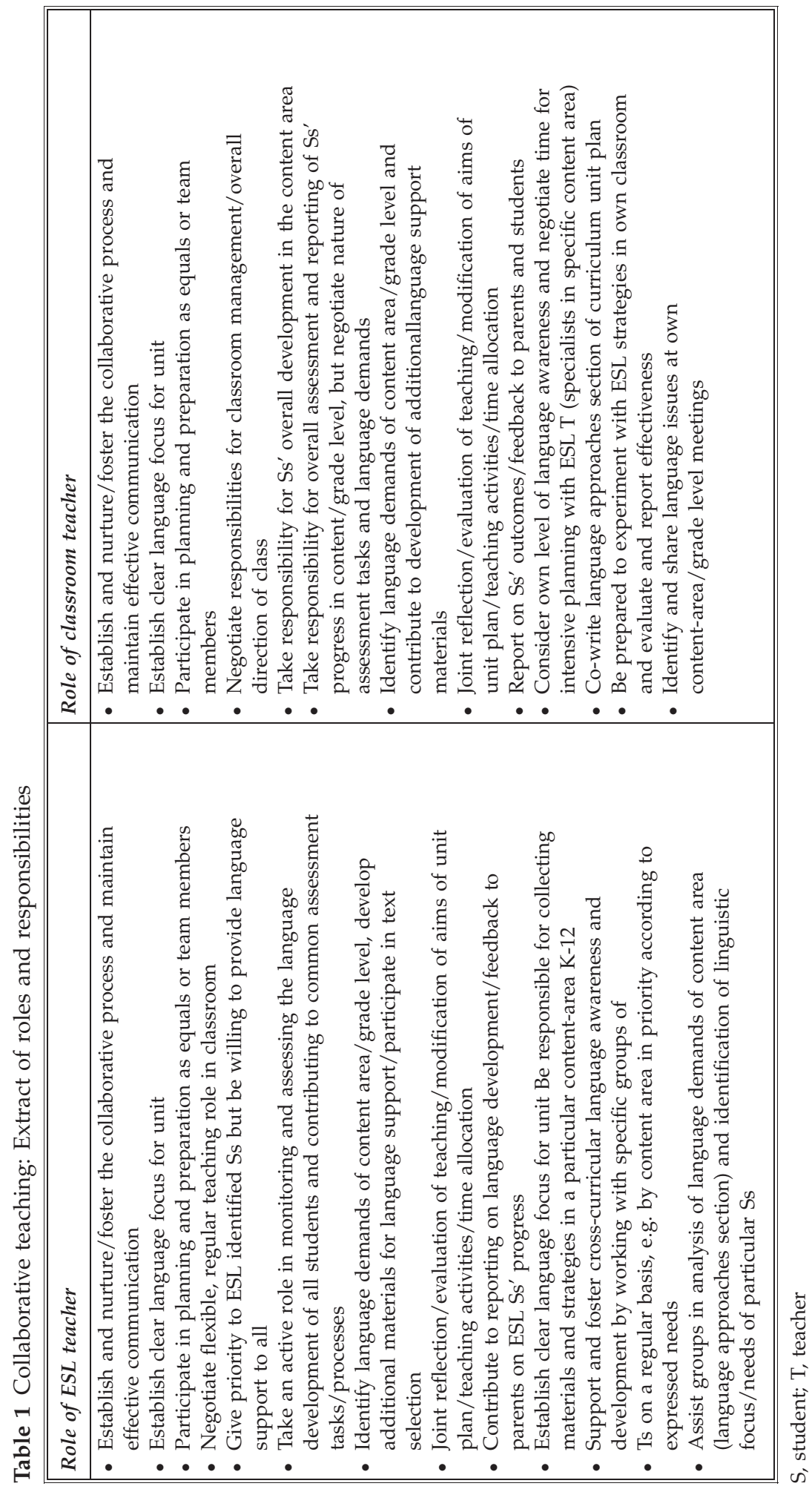


The methods of critical discourse analysis work well for examining the relation between text and context but must be balanced by opportunities for individuals to speak for themselves.

However, such an articulation of teacher beliefs needs to be treated as contextdependent, integral to the interaction between the participants, not simply as transparent and simplistic reflections of what goes on in the speaker or writer's mind. Meaning is not just in utterance (origination) but in response (orientation), thus rendering 'knowing' mutable and contingent rather than given and fixed (Bakhtin, 1981: 293-294). Teachers can be seen as simultaneously both rational, goal-directed agents (Giddens, 1984), who can explain why they do what they do, and social beings, whose positions within conversation are linguistically and socially constructed (Harre \& Gillet, 1994). Hence, I developed a dual, inter-related, reflexive analytical framework that linked the analysis of the context to that of the texts, employing the same descriptors as used for the textual analysis, but problematising them. I treated interactions between teachers not simply as texts, but as insights into participants' motivations and understandings. This allowed me to examine the 'situation of context' and its key elements in a more open and multilayered way than in most systemic approaches, and to capture multiple, changing and potentially contradictory discourses, situations, cultures and ideologies.

Within a Hallidayan model of language, the register of an interaction is seen in terms of three components: field, tenor and mode. Field refers to what the language is being used to talk about, the topic or content of the communication. Tenor refers to the roles and relationships between the interactants in a communication. Mode refers to how the language is organised as more spoken-like or more written-like. The way in which these three features of register offered a systematic way of describing the intellectual, the social and the organisational aspects of the teachers' discourse and the way in which I extended this framework to examine teacher beliefs about the context of situation will now be briefly described.

According to Martin (1986b: 19), field has to do with the inherent features of the situation and events taking place. These events and subject matter are seen as embedded in social processes, and constructed by the institutional nature of social settings, 'a set of activity sequences oriented to some global institutional purpose'. Martin (1992: 541) argues that 'the doings of a field' cannot be interpreted without some understanding of how its key concepts and participants, both animate and nonanimate, are organised and constructed. Martin (1992) highlights three specific ways in which aspects of field are realised ideationally - through lexical collocations (the co-occurrence of particular words), through references to people (as more or less abstract, more or less personal) and through the way in which processes are realised through the verbal system. My comparison of the discourse of less and more successful partnerships (as evaluated by the teachers themselves in their initial questionnaire) suggested that one of the indicators of a more successful collaboration was the way in which teachers adopted each others' language, especially technical terminology (e.g. lexis, outcomes) and content-specific 
formulaic phrases. Another marker appeared to be the use of more specific referents related to their joint work, such as syntax or grammar, rather than more abstract referents such as language. More successful collaboration also seemed to be characterised by teachers having more to say about specific individuals and what they saw, felt, thought and said, rather than relying on indefinite references to people (e.g. anyone, someone, many people) or generic references to people in a professional capacity, which removed the events and happenings from their specific context. Successful teacher collaboration appeared to be associated with a much higher level of behavioural, mental and verbal processes; less successful collaborations made more use of material and relational processes to talk in generalities about what had happened or what was, as if teachers has been stripped of all agency. In turning to analyse the situational context, I extended Martin's (1986b: 19) notion of field to define collaboration both as an institutional activity and as particular subject matter. I looked for recurring themes and concepts to understand how the participants conceptualised collaboration. I looked for links between the dominant concerns in a teacher's discourse, their conceptualisation of their partnership and their orientation towards collaboration.

The second element of register, tenor, has to do with the negotiation of social relations between speaker/writer and addressee, and includes status (equal or unequal), affect or expression of attitude (marked or unmarked, positive or negative) and contact (involved or distant) (Martin, 1992: 526). Status refers to the relative position of the interlocutors in a culture's social hierarchy, contact refers to their degree of institutional involvement with each other, and affect has been included, according to Martin (1992: 525) to cover what Halliday (1978: 33) refers to as the 'degree of emotional charge in the relationship between participants'. It is important to note that these elements are socially constructed by the participants, unlike elements of field, which refer to inherent characteristics within the situation. In systemics, tenor elements are conceptualised as clines, because they involve gradual rather than categorical distinctions. Martin (1986) highlights three specific ways in which these aspects of tenor are realised interpersonally in spoken discourse through 'amplification', 'reciprocity' and 'elaboration'. Amplification has to do with the intensity of the realisation, and in spoken language it is manifested in intensification (e.g. exclamatives, loudness, rising intonation) and repetition as well as through attitudinal lexis. Attitudinal lexis refers to the selection of lexis, which communicates something of the writer's judgements, appraisal or feelings about an issue, and reveals 'the positive or negative attitude of the speaker towards his listener or what he is talking about' (Martin, 1986a: 243). Affect is conceptualised as varying along a continuum from positive to negative, according to the degree of intensity. Reciprocity is marked by the use of more first and second personal reference (indicators of solidarity and agreement with an issue or person) through various choices from the mood and modal system, for example, through the use of more rhetorical questions and inclusive imperatives, as well as through the incorporation of more modulated appeals (e.g. 'We should do $X^{\prime}$ ). Elaboration reflects contact, the degree of involvement of the addresser with the addressee and is reflected in assumptions about shared knowledge, manifested in choices of topics within 
the text and in the degree of technical knowledge assumed about the topic. The more successful partnerships seemed to be characterised by more intensification when discussing the partnership and its achievements, and a greater range of first and second person reference to describe the collaborators, thus establishing the partnership as a more participatory, interactive, equal to equal relationship. The more successful partnerships also had more extended examples, quotes or references, which suggested greater contact between teachers, as well as, more obviously, concrete achievements. The less successful partnerships had more examples of hedging and uncertainty, particularly expressed through the modal system. In analysing the broader institutional context, I extended Martin's (1992: 526) notion of tenor to examine the negotiation of social relations between participants in interaction, to understand how the teachers conceptualised their roles in terms of affect, status and contact. I then looked for any links between participant's responses and their ESL orientation and speculated what the affect of different conceptualisations might be on actual discourse.

The third element of register, mode, is defined as semiotic distance, that is, how far the language of the text is from the world it describes. Mode thus mediates the role played by language along two dimensions: interpersonally, mode mediates the semiotic space between monologue and dialogue, or negotiation; experientially, mode mediates the semiotic space between action and reflection, or contextual dependency: 'the extent to which a text constructs or accompanies its field' (Martin, 1992: 509). In the various teachers' discourses, there are distinct differences in mode, in particular in the realisation of the theme and in the way other teachers are identified, and in the use of experiential metaphor. The more successful partnerships were characterised by more thematisation of human participants rather than things, making the discourse seem less abstract and less distant from the events being discussed. The discourse of successful partnership also made more use of congruent metaphors, hence creating a sense of agency. In analysing the broader situational context, I borrowed the notion of mode to analyse what teachers were prepared to write about (on the questionnaire) and what they preferred to say. This was a very rough and ready indicator but it did appear that the members of more successful partnerships not only had more to say, but were happier to say it in writing, which suggested a stronger commitment to the whole endeavour.

This analysis of the discourse and social positioning revealed in the questionnaire and interview data allowed me to build an emerging framework to describe five distinct stages of collaboration, and to draw out some of the implications for professional support and institutional change. This framework was first discussed with a number of the teacher-informants and other key stake-holders, and then revised. It is described in more detail below.

\section{An Emerging Framework for Describing Collaboration}

As a result of the process of extensive date collection and analysis, including member checking and triangulation, a framework to describe collaboration between ESL and classroom teachers at the elementary level 
was developed (see Table 2). It consists of five stages of increasing effectiveness in teacher collaboration. At the lowest level is pseudocompliance or passive resistance where there is distinct preference for a return to the old style pull-out programme and 'one teacher-one classroom'. The next level is compliance, exemplified by a generally positive attitude and expressions of good intent, with efforts made to implement collaborative roles and responsibilities albeit with only limited understanding of the implications. The next stages are more positive, moving from accommodation, with its strong emphasis on practical implementation to convergence (and some co-option of the other teacher's beliefs and practices) to creative co-construction where co-teaching is highly intuitive and creative and the parameters of the partnership very fluid (cf. Berliner, 1986). Four distinct areas of teacher concern were identified as indicators of each stage, roughly grouped under the following headings: attitude, effort, achievements and expectations of support. Each of these aspects of collaboration will be elaborated in turn, exemplified with comments from the data from both classroom and ESL teachers.

The first and perhaps most interesting aspect of the analysis of the stages of development in partnership teaching are the findings on teacher attitudes. Even in this well resourced school, where the administration was strongly supportive of collaborative teaching and provided much infrastructure, guidance and support, and where teachers were encouraged to continually renegotiate their roles, there are still clear differences in attitudes towards the whole idea of partnership. A few teachers demonstrate a lack of compliance, or at best, passive resistance with an implicit or explicit rejection of collaboration, and a preference for the status quo: 'Someone more experienced with ESL needs to take my place' (CT3), with the indefinite referent signalling a distancing of the teacher from the whole notion of partnership. In contrast, compliant teachers believe that they should support the idea because it was best for the children although they were not convinced that it was necessarily best for them: 'It's best for the children' (CT1); 'Children learn best being immersed in classroom' (CT6); 'All the children benefit from having another person in the room' (CT7). Their rather formulaic phrases are very much a reflection of an elementary, rather than ESL, orientation, with little evidence of any use of ESL-specific language. In contrast, the accommodating teacher shows a more positive attitude and a willingness to experiment: 'There are still many things I need to learn in working with this new model. There have been moments when things worked really well and I got a glimpse of how it can be successful' (ESL1). Convergent teachers are even more positive, embracing opportunities to learn from peers: 'I have enjoyed it and am convinced it is the way to go. I would like to develop an even more successful model and build my own knowledge and skills' (CT2); 'I felt included in the programme' (ESL3). At the most successful level of development there are teachers who feel they have benefited greatly from the experience, with collaboration normalised and seen as the preferred option for ESL teaching, and the teachers' roles viewed as both more interchangeable, yet more distinct: 'Teaching a sheltered immersion class has been one of the most successful experiences of my career. I benefited daily from the expertise of the ESL immersion teacher' (CT5). The 


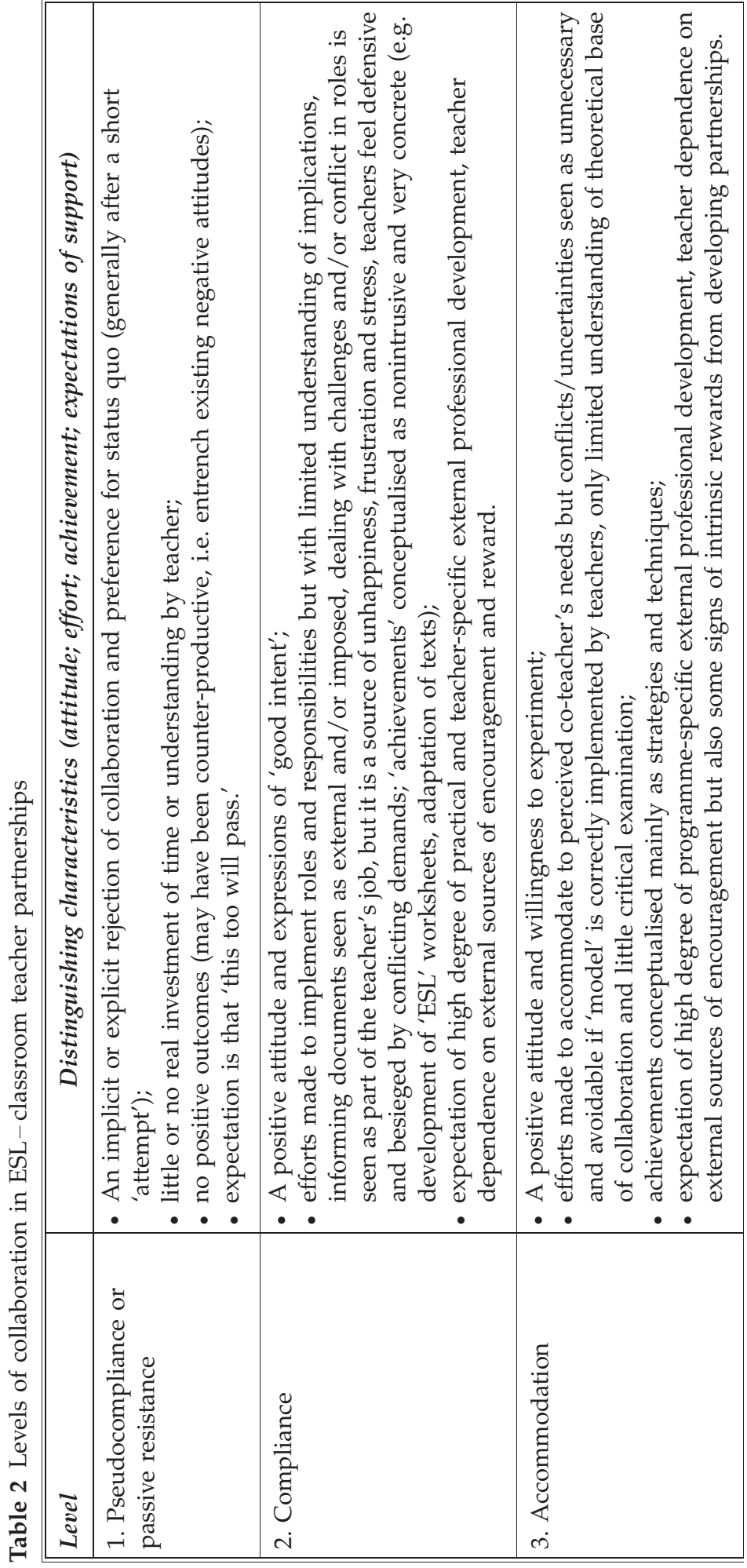




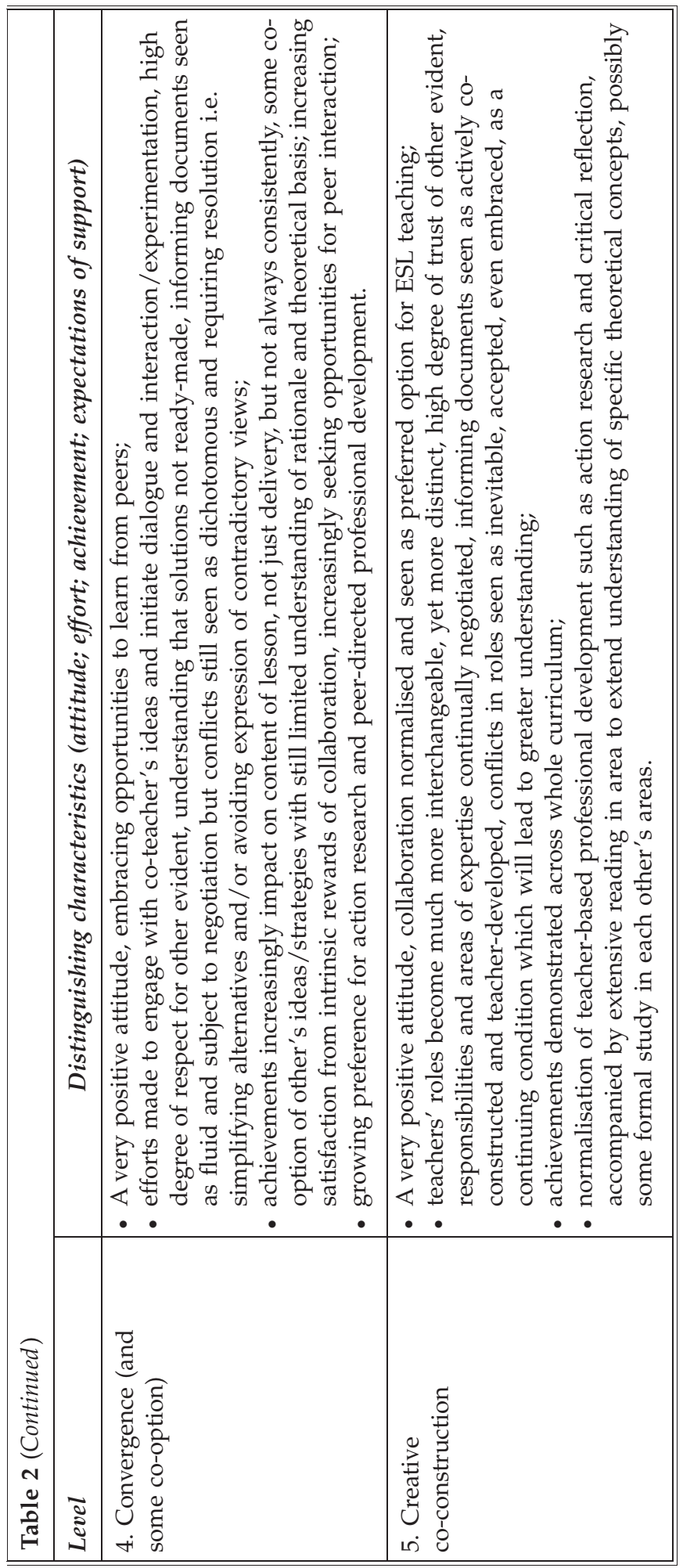


adoption of the linguistic labels used by the ESL teachers as well as the use of definite referents reinforce the sentiments expressed by the teacher.

In terms of effort, similar patterns can be seen. The lowest stage of development is marked by little or no real investment of time or understanding: "Tell me "how" I need to assist each student and provide me with modified versions of what is planned ... instead of giving suggestions, give complete lessons that address specific needs that are seen' (CT3), the imperative addressed to the world at large signalling a fair degree of frustration and distance. At the next level, compliance, dealing with challenges and/or conflict in roles is seen as part of the teacher's job, but it is a source of unhappiness, frustration and stress, with teachers feeling defensive and besieged by conflicting demands: 'The job description sheet ...needs to be looked at so that all parties know what/where their responsibilities are. Someone needs to ensure roles are followed... Both teachers need to be responsible for planning, assessing and record keeping' (CT1). Concerns are still discussed in general terms, as if they transcend the specific context. In contrast, an accommodating teacher makes efforts to adjust and adapt to a co-teacher's perceived needs but conflicts are still seen as unnecessary and avoidable if the partnership 'model' is correctly implemented by teachers: 'I found myself struggling to find the balance between the content and language needs of the ESL students and often ended up with not enough time to address language needs adequately' (ESL1). At this level there is only limited understanding of the theoretical base of collaboration and little critical examination: 'I felt I had to take the initiative during the planning sessions. Originally...there was not a lot a focus and not the best use was being made of the ESL teachers' time. Sometimes I feel there are differing philosophies and understandings of issues like learning styles, child and language development, behaviour management etc.' (CT2). In contrast, the converging teacher makes explicit efforts to engage with the co-teacher's ideas and initiate dialogue and interaction/experimentation: 'I always wanted to do more' (ESL 3). A high degree of respect for the other teacher is evident, but conflicts are still seen as dichotomous and requiring resolution, that is, simplifying alternatives and/or avoiding contradictory views. At both levels the sense of personal responsibility and agency is construed through the use of specific referents and congruent interpersonal metaphor. An even greater degree of trust is demonstrated at the highest level of partnership, with responsibilities and areas of expertise continually being negotiated, and guidelines such as the teacher's planning proforma actively co-constructed: 'We are constantly trying different strategies to accommodate the various learning styles of the students in this class' (CT5). The shift from ' $\mathrm{I}$ ' to 'we' at this level is an important indicator of the success and self-sustainability of the partnerships. Role conflicts appear to be seen as inevitable, and accepted, even embraced, as a continuing condition that will eventually lead to greater understanding.

In terms of achievement, again a similar pattern across the five stages of partnership can be seen. At the lowest levels of effectiveness, no positive outcomes are perceived by the teachers, with the partnership in fact counter- 
productive, entrenching existing negative attitudes: 'Too time consuming. . schedule not suited to our needs' (CT4). Here the pronoun our refers not to the co-teachers and their timetable, but to the community of classroom teachers with which this teacher still strongly identifies. Its use negates any sense of collaborative endeavour. At the next level, compliance, achievements are conceptualised as nonintrusive, concrete (for example, the development of 'ESL' worksheets and the adaptation of texts) and not always consistent: 'There didn't appear to be any plans for the individual needs of the ESL learners other than what the classroom teacher did' (CT1). The teacher refers to herself in the third person, again a distancing device that suggests the partnership is less than effective. At the level of accommodation achievements are conceptualised mainly at the level of strategies and techniques: 'I feel there has been a gap between my expertise as a classroom teacher and the ESL teachers' knowledge. . I thought that the ESL teacher would have a repertoire of strategies that would be appropriate for use in the mainstream class but this has not been the case and as I do not have the ESL strategies or understanding of the language structures, I am worried that the students may have missed out on some important skills/understandings they need to develop.' (CT2); 'It was our hope that the ESL teacher would have language strategies to offer and assist in our planning. Unfortunately this is rarely the case' (CT7). The pronoun our is still used to exclude rather than include the collaborating ESL teacher, and the use of past tense and conditional again distances the activity. A specific event is turned into a generalisation that is framed in ways that are hard to challenge. However, the use of more specific referents suggests some positive shift in tenor, even though the teachers' concerns are still very practical and self-oriented. In contrast, at the level of convergence achievements are conceptualised in terms of their impact on the content of the lessons, not just the delivery, although not always consistently. There was some cooption of other's ideas/strategies, but with still limited understanding of the rationale and theoretical basis: 'The class teachers and I need to work on a more organised plan...this year, with no curriculum to peruse in advance, much of our scaffolding was last minute' (ESL3). The use of the pronoun our here construes the endeavour as shared and collaborative. At the highest level of partnership effectiveness, achievements are seen as impacting across the whole curriculum: 'While I feel the language needs of the ESL learners are being met. . I feel the situation can be improved by nailing down the thematic units ahead of time' (CT5). The use of present progressive conveys the sense of the partnership as an ongoing and immediate activity, and the explicit congruent use of modality and repetition of 'I feel' shows classroom teacher personalising the task, and taking responsibility for the direction of the partnership.

In terms of expectations of support, again there are similar patterns in the indicators of partnership effectiveness. At the lowest levels there is an expectation that this is short-lived innovation, which will soon pass: 'It seems obvious to me that only classroom teachers with ESL training will feel comfortable in this role' (CT 3). The reference to a general class rather than specific people reveals a refusal to take any responsibility for the success of the partnership. At the level of compliance, there is an expectation of a high 
degree of practical and teacher-specific external professional development, with an obvious teacher dependence on external sources of encouragement and reward and a concern about practical barriers to effective implementation: 'Large blocks of time are needed if proper planning is to take place' (CT1), 'There is insufficient planning time' (CT7); '(The school) should provide more training - to all teachers involved' (CT3), 'More workshops for ESL teachers on best primary practices so that their teaching and understanding is in alignment with ours' (CT 6); 'Too many classes in first semester' (ESL2). At the level of accommodation there is an expectation of a high degree of programme-specific external professional development, still with obvious teacher dependence on external sources of encouragement but also some signs of intrinsic rewards from the developing partnership: 'Recruit classroom teachers who are willing to work with the model and whose teaching styles lend themselves to the model' (ESL1). Increasing satisfaction with the intrinsic rewards of collaboration is a feature of the next level, convergence, with teachers increasingly seeking opportunities for peer interaction, and demonstrating a growing preference for action research and peer-directed professional development: 'I would like to see change so that class teachers are given professional development in ESL strategies (and) immersion teachers given professional development in classroom management and other examples of "best practice" - guided reading, writing process, oral language activities' (CT2). The referents become more specific and the use of first person signals a higher level of engagement with partnership. At the highest level there is a normalisation of teacher-based professional development such as action research and critical reflection, accompanied by extensive reading in area to extend understanding of specific theoretical concepts, accompanied by some formal study in each other's area, revealed in teachers' echoing of each others' technical terminology, as in this example of a classroom teacher talking about grammatical progressions: 'There has been insufficient time to plan for the language implications of the content we are teaching; for example, the development of grammatical progressions. This is because we are still developing thematic units the planning of which must precede attention to their language aspects' (CT5).

Perhaps not surprisingly, ESL teachers were generally more positive than classroom teachers about collaboration. They did not demonstrate any overt resistance to partnership, but they were guarded in their responses to success, perhaps because they had higher expectations than the classroom teachers of the whole enterprise, or perhaps because they were still coming to terms with the more challenging shift in their role and responsibilities, and the consequent greater loss of ownership and control. As in Berliner's (1986) model of teacher development described earlier, despite a common starting time and common input, partnerships appeared to develop at different speeds from different stages or starting points, and only a few were perceived as really successful. Like Berliner, the first two stages seem characterised by deliberation in action and thinking as well as by a reluctance to take full responsibility for actions. In contrast the third stage, accommodation, was marked by more deliberate and conscious actions and rational goals. The two highest stages of collaboration were marked by increasing levels of intuition, 
fluidity and 'knowing-in action'. However, it is not clear from the data whether the stages identified above were a continuum of development, that is, whether a partnership necessarily had to move through each stage. Certainly some partnerships, through a combination of personal and situational factors, appeared to progress much more rapidly and much further than others. A detailed analysis of teacher background, qualification and experience did not reveal any strong correlations between these factors and a successful partnership, but closer analysis of the longitudinal data may reveal certain teacher attributes that predispose a partnership to greater success. However, a number of conclusions about successful collaboration and implications for professional development and institutional change can be drawn from the findings of this study. These will be discussed below.

\section{Conclusions and Implications}

Among the many conclusions that can be drawn from this study is that partnership between ESL and classroom teachers is neither easy nor unproblematic, even in a well resourced elementary school in which ESL student needs are seen as paramount and teachers appear to have a relatively loose identification with their teaching areas. Teacher attitudes and effort varied dramatically depending on the level of collaboration, with distinct stages, from survival self-concerns, where teachers struggled to adapt to routines and were reluctant to change, to a gradual awareness of the impact of collaboration on students, to a readiness to respond to feedback on teaching. This is also reflected in the teachers' perceptions of their achievements, with a clear move from teacher emphasis on relatively superficial strategies to a concern with curriculum. The nature of the institutional and professional development support expected also seemed be very different at different stages of collaboration, with preferences shifting from very concrete, externally constructed support to more internally directed activity as the collaborations are perceived to be more successful. One of the implications for professional development is that collaborating teachers may benefit from more actionorientated teacher research with built-in opportunities for critical reflection and discussion of different views and perceptions of the nature of learning and teaching.

More research is obviously needed to evaluate whether this framework is valid for different schools and different levels of schooling. The range and scope of case studies of successful (or less successful) partnership practices needs to be extended as a matter of urgency and more discourse-based studies of collaborative classrooms and of team planning conversations undertaken. Most importantly we need to research the effect of different forms of partnership on students through large-scale longitudinal studies of English language and subject content development in 'partnership' schools and international comparative studies of the effectiveness of collaborative approaches to teaching. 


\section{Acknowledgements}

I would like to express my sincere gratitude to all those who helped with this study, in particular the teacher informents who made it possible.

\section{Correspondence}

Any correspondence should be directed to Dr Chris Davison, Faculty of Education, University of Hong Kong, R. 125, Hui Oi Chow Building, Pokfulam, Hong Kong, SAR (cdavison@hkucc.hku.hk).

\section{Notes}

1. The title of a video on collaborative teaching made by the Catholic Education Office, Victoria in the late 1980s.

2. See Arkoudis (1995) for actual examples of such distortion among mathematics and science teachers.

\section{References}

Arkoudis, S. (1995) Clash of cultures: Mainstream teachers' working knowledge and English as a second language (ESL) pedagogy. Unpublished MEd Minor Thesis, University of Melbourne.

Arkoudis, S. (2000) 'I have linguistic aims and linguistic content': ESL and science teachers planning together. Prospect 15 (2), 61-71.

Arkoudis, S. (in press) Collaborative teaching. In J. Cummins and C. Davison (eds) International Handbook of English Language Teaching. Norwell, MA: Springer.

Arkoudis, S. and Davison, C. (2002) Breaking out of the billabong: Mainstreaming ESL in Australia. In E. Cochran (ed.) Case Studies in TESOL: Mainstreaming (pp. 53-70). Alexandria, VA: TESOL.

Bakhtin, M. (1981) The Dialogic Imagination: Four Essays (C. Emerson and M. Holoquist, trans.) Austin, TX: University of Texas Press.

Berliner, D. (1986) In pursuit of the expert pedagogue. Educational Researcher 15 (7), 5-13.

Bourne, J. (1989) Moving into the Mainstream: LEA Provision for Bilingual Pupils. Windsor: NFER-Nelson.

Bourne, J. (1997) The continuing revolution: Teaching as learning in the mainstream multilingual classroom. In C. Leung and C. Cable (eds) English as an Additional Language (pp. 77-88). York: NALDIC.

Bourne, J. and McPake, J. (1991) Partnership Teaching: Co-operative Teaching Strategies for Language Support in Multilingual Classrooms. London: HMSO.

Brinton, D. and Master, P. (eds) (1997) New Ways in Content-Based Instruction. Alexandria, VA: Teachers of English to Speakers of Other Languages.

Brinton, D., Snow, M. and Wesche, M. (1989) Content-based Language Instruction. Philadelphia: Newbury House.

Burden, P. (1990) Teacher development. In W. Houston, M. Haberman and J. Sikula (eds) Handbook of Research on Teacher Education (pp. 311-328). New York: Macmillan.

Calderhead, J. and Shorrock, S. (1997) Understanding Teacher Education: Case Studies in the Professional Development of Beginning Teachers. London: Falmer.

Cheung, D. and Ng, D. (2000) Teachers' stages of concern about the target-oriented curriculum. Education Journal 28 (1), 109-122.

Corrie, L. (1995) The structure and culture of staff collaboration: Managing meaning and opening doors. Educational Review 47 (1), 89-99.

Crandall, J. (1987) ESL through Content-area Instruction. Englewood Cliffs, NJ: Prentice Hall Regents.

Crandall, J. and Kaufmann, D. (eds) (2002) Case Studies in TESOL: Content-based Instruction in Higher Education Setting. Alexandria, VA: TESOL. 
Crandall, J., Spanos, G., Christian, D., Simich-Dudgeon, C. and Willetts, K. (1987) Integrating Language and Content Instruction for Language Minority Students. Washington, DC: National Clearing House for Bilingual Education.

Creese, A. (2000) The role of language specialists in disciplinary teaching: In search of a subject? Journal of Multilingual and Multicultural Development 21 (6), 451-470.

Creese, A. (2002) The discursive construction of power in teacher partnerships: Language and subject specialists in mainstream schools. TESOL Quarterly 36 (2), 597-616.

Davison, C. (1992) Look out! Eight fatal flaws in team and support teaching. TESOL in Context 2 (1), 10-13.

Davison, C. (2001a) Current policies, programs and practices in school ESL. In B. Mohan, C. Leung and C. Davison (eds) English as a Second Language in the Mainstream: Teaching, Learning and Identity (pp. 30-50). London: Longman Pearson.

Davison, C. (2001b) ESL in Australian schools: From the margins to the mainstream. In B. Mohan, C. Leung and C. Davison (eds) English as a Second Language in the Mainstream: Teaching, Learning and Identity (pp. 11-29). London: Longman Pearson.

Davison, C. (2001c) Identity and ideology: The problem of defining and defending ESLness. In B. Mohan, C. Leung and C. Davison (eds) English as a Second Language in the Mainstream: Teaching, Learning and Identity (pp. 71-90). London: London Pearson.

Davison, C. and Williams, A. (2001) Integrating language and content: Unresolved issues. In B. Mohan, C. Leung and C. Davison (eds) English as a Second Language in the Mainstream: Teaching, Learning and Identity (pp. 51-70). London: Longman Pearson.

de Jong, O. (2000) The teacher trainer as researcher: Exploring the initial pedagogical content concerns of prospective science teachers. European Journal of Teacher Education 23 (2), 127-137.

Early, M. (2001) Language and content in social practice: A case study. Canadian Modern Language Review 58 (1), 156-179.

Education Department of South Australia (1991) ESL in the Mainstream, Workshops 1-5. Adelaide, SA: Government Printer.

Fuller, M. and Brown, S. (1975) Becoming a teacher. In K. Ryan (ed.) Teacher Education (pp. 25-52). Chicago: University of Chicago Press.

Furlong, J. and Maynard, T. (1995) Mentoring Student Teachers: The Development of Professional Knowledge. London: Routledge.

Ghaye, A. and Ghaye, K. (1998) Teaching and Learning through Critical Reflective Practice. London: David Fulton Publishers.

Giddens, A. (1984) The Constitution of Society. Cambridge: Polity Press.

Glaser, B. and Strass, A. (1967) The Discovery of Grounded Theory: Strategies for Qualitative Research. New York: Aldine.

Halliday, M. (1985) An Introduction to Functional Grammar. London: Edward Arnold.

Halliday, M.A.K. and Hasan, R. (1985) Language Context and Text: Aspects of Language in a Social-Semiotic Perspective. Geelong: Deakin University Press.

Hargreaves, A. (1994) Collaboration and contrived collegiality: Cup of comfort or poisoned chalice? In A. Hargreaves (ed.) Changing Teachers, Changing Times (pp. 186-211). London: Cassell.

Hargreaves, A. and Macmillan, B. (1994) The balkanisation of teaching: Collaboration that divides. In A. Hargreaves (ed.) Changing Teachers, Changing Times (pp. 212-240). London: Cassell.

Harre, R. and Gillet, G. (1994) The Discursive Mind. London: Sage.

Hurst, D. and Davison, C. (2005) Collaboration on the curriculum: Focus on secondary ESL. In J. Crandall and D. Kaufman (eds) Case Studies in TESOL: Teacher Education for Language and Content Integration. Alexandria, VA: Teachers of English to Speakers of Other Languages.

Kagan, D. (1992) Professional development among preservice and beginning teachers. Review of Educational Research 62 (2), 129-169.

Lave, J. and Wenger, E. (1991) Situated Learning, Legitimate Peripheral Participation. Cambridge: Cambridge University Press. 
Little, J. (1990) Teachers as colleagues. In A. Lieberman (ed.) Schools as Collaborative Cultures: Creating the Future Now (pp. 165-193). London: Falmer.

Lortie, D. (1975) Schoolteacher: A Sociological Study. Chicago: University of Chicago Press.

Martin, J.R. (1986a) Grammaticalising ecology: The politics of baby seals and kangaroos. In T. Threadgold, E. Grosz, G. Kress and M. Halliday (eds) Semiotics Ideology Language (Vol. 3, pp. 225-268). Sydney: Sydney Association for Studies in Society and Culture.

Martin, J.R. (1986b) Intervening in the process of writing development. In C. Painter and J.R. Martin (eds) Writing to Mean: Teaching Genres Across the Curriculum (Occasional Papers No. 9, pp. 11-43). Sydney: Applied Linguistics Association of Australia.

Martin, J.R. (1992) English Text: System and Structure. Amsterdam: John Benjamins.

Miles, M. and Huberman, M. (1984) Qualitative Data Analysis: A Sourcebook of New Methods. Beverly Hills, CA: Sage.

Mohan, B. (1986) Language and Content. Reading, MA: Addison-Wesley.

Mohan, B. and Lowe, M. (1995) Collaborative teacher assessment of ESL writers: Conceptual and practical issues. TESOL Journal 5 (1), 28-31.

Roth, W. and Tobin, K. (2004) Co-teaching: From praxis to theory. Teacher and Teaching: Theory and Practice 10 (2), 161-180.

Seliger, H. and Shohamy, E. (1989) Second Language Research Methods. Oxford: Oxford University Press.

Short, D. and Echevarria, J. (1999) The Sheltered Instruction Observation Protocol: A Tool for Teacher-Researcher Collaboration and Professional Development. Santa Cruz, CA and Washington, DC: Center for Research on Education, Diversity and Excellence.

Siskin, L. (1994) Realms of Knowledge: Academic Departments in Secondary Schools. London: Falmer.

Snow, C.M., Met, M. and Genesee, F. (1989) A conceptual framework for the integration of language and content in second/foreign language instruction. TESOL Quarterly $23(2), 201-219$.

Stake, R. (1978) The case study method in social inquiry. Educational Researcher February, 5-8.

Thesen, L. (1997) Voices, discourse and transition: In search of new identities in EAP. TESOL Quarterly 31 (3), 487-512.

Tsui, A. (2003) Understanding Expertise in Teaching. Cambridge: Cambridge University Press.

Van Manen, M. (1997) Linking ways of knowing with ways of being practical. Curriculum Inquiry 6, 205-228.

Zeichner, K. and Liston, D. (1996) Reflective Teaching: An Introduction. Mahwah, NJ: Lawrence Erlbaum. 